\title{
Hippocampal atrophy and verbal episodic memory performance in amnestic mild cognitive impairment and mild Alzheimer's disease A preliminary study
}

\author{
Nathalia Carollina Peruzza Marchiani ${ }^{1}$, Marcio Luiz Figueredo Balthazar ${ }^{2}$, \\ Fernando Cendes ${ }^{3}$, Benito Pereira Damasceno ${ }^{4}$
}

\begin{abstract}
To evaluate hippocampal volume in patients with AD and aMCI, and correlate its atrophy with verbal episodic memory performance. Methods: We studied 42 individuals older than 50 years, including 14 with amnestic mild cognitive impairment (aMCI), 14 with mild Alzheimer's disease (AD) and 14 normal controls. All individuals were submitted to the Rey auditory verbal learning test (RAVLT) to evaluate episodic memory. They were also submitted to the forward (FDS) and backward digit span (BDS) subtest of WAIS-R to evaluate working memory and attention, and to the Mini Mental State Examination (MMSE). Hippocampal volumetric measurements were performed according to anatomic guidelines from a standard protocol using high-resolution T1-inversion recovery 3-mm coronal MRI slices. Hippocampal volumes (HV) were corrected for the variation in total intracranial volume. There was no significant difference between the three groups concerning age and education. Results: On RAVLT, there was a continuum between the three groups, with AD recalling less words, controls more, and aMCI subjects showing an intermediate performance on all sub-items. We found an asymmetry between HVs, with smaller mean left HV for all groups. ANOVA and post hoc Tukey's test for comparisons of HV showed a significant difference among groups, with difference between controls and both AD and aMCI, although there was no significant difference between $\mathrm{AD}$ and $\mathrm{aMCI}$ groups. Conclusions: There was a significant correlation between hippocampal volumes and scores on RAVLT, confirming that medial temporal structures are closely associated with memory performance in normal ageing as well as in aMCI and AD.
\end{abstract}

Key words: hippocampal atrophy, MRI, memory, Alzheimer's disease, mild cognitive impairment.

\begin{abstract}
Atrofia hipocampal e desempenho na memória verbal episódica no comprometimento cognitivo leve amnéstico e na doença de Alzheimer leve

Resumo - Avaliar os volumes hipocampais (VH) em pacientes com doença de Alzheimer (DA) leve e comprometimento cognitivo leve amnéstico (aCCL). Métodos: Estudamos 42 sujeitos maiores de 50 anos, incluindo 14 com DA leve, 14 com aCCL e 14 controles. Todos foram submetidos ao teste de aprendizado auditivo verbal de Rey (TAAVR) para avaliação de memória episódica, ao teste de extensão de dígitos direto e indireto do WAIS-R, para avaliação de memória operacional e atenção e ao Mini Exame do Estado Mental (MEEM). As medidas de volumetria hipocampal foram obtidas de acordo com as diretrizes anatômicas de um protocolo padrão usando imagens coronais ponderadas $\mathrm{T} 1$ inversion-recovery de $3 \mathrm{~mm}$. Os VH foram corrigidos para a variação do volume intracraniano total. Não houve diferença significativa entre os 3 grupos quanto a idade e escolaridade. Resultados: No TAAVR houve um continuum no desempenho dos 3 grupos, com os pacientes com DA leve evocando menos palavras, os controles mais e os aCCL mostrando um desempenho intermediário em todos os subitens.
\end{abstract}

${ }^{1}$ Graduate student. ${ }^{2} \mathrm{MD}, \mathrm{PhD}$ student. ${ }^{3} \mathrm{MD}$, PhD, Associate Professor. ${ }^{4} \mathrm{MD}, \mathrm{PhD}$, Professor. Department of Neurology; Medical School, State University of Campinas (UNICAMP).

Benito Pereira Damasceno - Department of Neurology / Medical School / State University of Campinas - Box 6111 - 13083-970 Campinas SP - Brazil. E-mail: damascen@unicamp.br

Received 01/25/2008. Received in final form 02/15/2008. Accepted 02/16/2008. 
Encontramos também uma assimetria entre os $\mathrm{VH}$, com o lado esquerdo menor que o direito nos 3 grupos. O teste de análise de variância (ANOVA) seguido do teste post hoc de Tukey para comparações entre os VH dos grupos mostrou diferença significativa entre controles e DA e aCCL, mas não entre DA e aCCL. Encontramos também correlação estatística significativa entre os VH e o desempenho no TAAVR. Conclusões: As estruturas do lobo temporal medial estão intimamente ligadas ao desempenho de memória episódica tanto no envelhecimento normal quanto no aCCL e DA.

Palavras-chave: atrofia hipocampal, MRI, memória, doença de Alzheimer, transtorno cognitivo leve.

Memory is a complex psychological function that is closely associated with medial temporal lobe structures. Since the H.M. case described in the early 1950s, it has been known that circumscribed brain lesions within the limbic system may deteriorate the ability to form new memories. ${ }^{1}$

Patients with Alzheimer's disease (AD) and amnestic mild cognitive impairment (aMCI) show a markedly reduced ability to retain new information: they often have difficulty in recalling appointments, shopping list items, names of people, and perform poorly on verbal episodic memory tests. This memory impairment is the earliest clinical symptom and a prominent feature throughout the course of $\mathrm{AD}^{2,3}$

The hippocampus is a central component of the medial temporal lobe memory system, and its structural integrity is necessary for declarative memory. ${ }^{1,2}$ There are several neuroimaging evidences for loss of hippocampal tissue in human diseases associated with memory impairments, and findings of magnetic resonance imaging (MRI) studies have established that volumetry of the hippocampus is useful in assisting the clinical diagnosis of $\mathrm{AD}^{4-6} \mathrm{In}$ patients with aMCI, a condition that is often transitional to $\mathrm{AD}$, hippocampal cortex pathology lies between the values measured in controls and mild AD. ${ }^{7}$

In the present study, our aim was to evaluate hippocampal volume in patients with $\mathrm{AD}$ and $\mathrm{aMCI}$, and correlate its atrophy with verbal episodic memory performance.

\section{Patients and methods}

We studied 42 individuals older than 50 years, comprising 14 with aMCI, 14 with mild AD attended at the Unit for Neuropsychology and Neurolinguistics (UNICAMP Clinic Hospital), and 14 normal controls. Routine laboratory examinations for dementia assessment (including B12 and folate dosage, serology for syphilis, thyroid hormones) and brain computed tomography were carried out in all patients. The local ethics committee approved this research.

aMCI in our clinic is a diagnosis carried out by trained neurologists using a standardized mental state battery. The diagnostic process consisted of a detailed interview with the patient and informant. All patients were submitted to the Cambridge Mental Disorders of the Elderly Examination
(CAMDEX) which comprises structured interviews with the patient and, separately, with an informant, along with evaluation of patient's current medical and psychiatric status and family history. Participants were also submitted to the CAMDEX cognitive test battery (CAMCOG), which includes eight subscales: memory, orientation, language, attention, abstract thinking or similarities, calculation and perception. ${ }^{8}$

MCI diagnosis followed the criteria of the International Working Group on Mild Cognitive Impairment, ${ }^{9}$ and was classified as follows: (i) the person is neither normal or demented; (ii) there is evidence of cognitive deterioration shown by either objectively measured decline over time and/or subjective self-report of decline and/or by informant in conjunction with objective cognitive deficits; and (iii) activities of daily living are preserved and complex instrumental functions are either intact or minimally impaired.

We considered a diagnosis of aMCI if the clinical history and cognitive performance pointed to an exclusive memory deficit and Clinical Dementia Rating ${ }^{10}$ score of 0.5 , with obligatory memory score of 0.5 . This classification was achieved using a semi-structured interview.

For probable AD diagnosis, we used the criteria of the National Institute of Neurological and Communicative Disorders and Stroke (NINCDS) and Alzheimer's Disease and Related Disorders Association (ADRDA) ${ }^{11}$ including only patients classified as CDR 1. Exclusion criteria were history of other neurological or psychiatric diseases, head injury with loss of consciousness, use of sedative drugs in the last 24 hours before the neuropsychological assessment, drug or alcohol addiction and prior chronic exposure to neurotoxic substances. The control group consisted of subjects with CDR 0 without previous history of neurological or psychiatric disease, or memory complaints.

All individuals were submitted to the Rey auditory verbal learning test (RAVLT $)^{12}$ to evaluate episodic memory, which consists of fifteen words read aloud for five consecutive trials (List A), followed by a free-recall test. We considered immediate memory the mean of these five trials. After the fifth trial, a new interference list of fifteen words is presented (List B) followed by a free-recall test of that list. Soon afterwards, a free-recall of the first list is tested without representation. After a twenty-minute delay period, 
subjects are again required to recall words from List A (delayed recall). Finally, the patient must identify List A words from a list of fifty words which includes Lists A and B and twenty other words phonemically or semantically related to lists A and B (recognition). They were also submitted to the forward (FDS) and backward digit span (BDS) subtest of WAIS-R ${ }^{13}$ to evaluate working memory and attention, as well as to the Mini Mental State Examination (MMSE). ${ }^{14}$

\section{MRI volumetry}

MRI acquisition was performed on a 2-T scanner (Elscint Prestige ${ }^{\circledR}$, Haifa, Israel), in three orthogonal planes, and a volumetric saggital $\mathrm{T} 1$ acquisition for multiplanar reconstruction. Hippocampal volumetric measurements were performed according to anatomic guidelines from a standard protocol ${ }^{15}$ in T1-IR 3-mm coronal slices (flip angle $=200^{\circ} ; \mathrm{TR}=2800, \mathrm{TE}=14$, inversion time $(\mathrm{TI})=840$, matrix $130 \times 256, F O V=16 \mathrm{~cm} \times 18 \mathrm{~cm}$ ). We performed manual delineation of the entire extension of hippocampal formation using the NIH-Image program ${ }^{\circledR}$ (developed at the United States National Institutes of Health and available on the Internet at http://www.rsb.info.nih.gov/nih-image/).
Hippocampal volumes (HV) were corrected for the variation in total intracranial volume, and asymmetry indexes were determined for each subject as the ratio of the smaller to the larger hippocampus. Volumes were transformed into $Z$ scores: number of standard deviations from the mean of control group. $Z$ scores below -2.0 were indicative of atrophy. The investigators who interpreted MRIs and performed MRI volumetric measurements were blinded to patients' clinical and neuropsychological information.

Data analysis by means of Systat software used ANOVA and a post-hoc Tukey test for group comparisons of demographic, cognitive and volumetric scores. Multiple linear regressions were used to compare RAVLT scores with other relevant variables. Statistical significance considered was $\mathrm{p}<0.05$.

\section{Results}

As shown in Table 1, there was no significant difference between the three groups concerning age $[\mathrm{F}(3,39)=3.105$, $\mathrm{p}=0.056]$ and education $[\mathrm{F}(3,39)=0.196, \mathrm{p}=0.822]$. On RAVLT, there was a continuum between the three groups, with $\mathrm{AD}$ recalling less words, controls more, and aMCI sub-
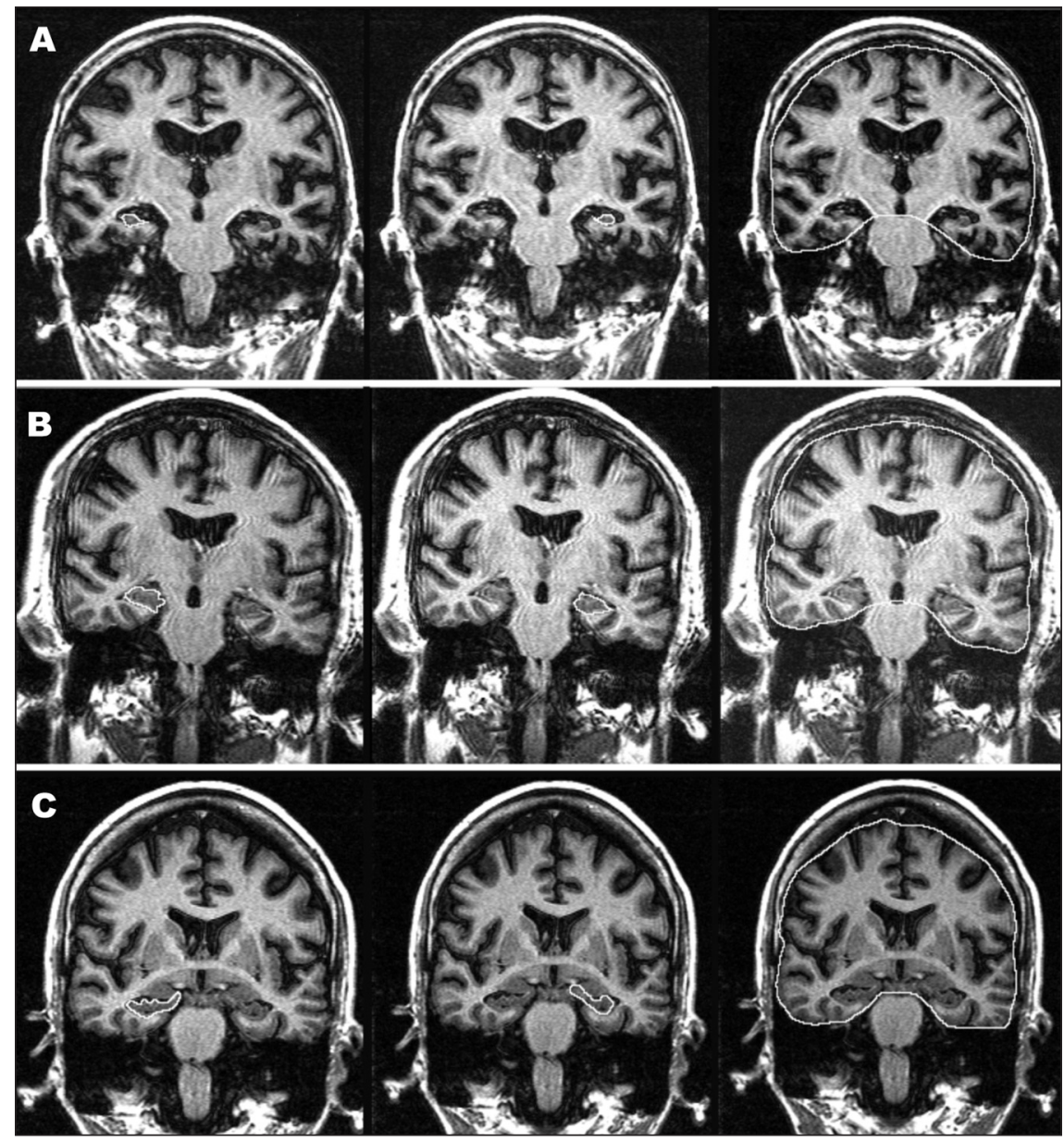

Figure 1. Illustrative pictures of $T 1-I R$ coronal slice delineation of the entire extension of right and left hippocampal formation and intracranial volume. (A) Mild AD; (B) aMCI; (C) Normal controls. 
Table 1. Demographic and neuropsychological data.

\begin{tabular}{lccc}
\hline & AD $($ mean \pm SD) & aMCI (mean \pm SD) & Controls (mean \pm SD) \\
\hline Age & $75.07 \pm 6.90$ & $68.14 \pm 9.75$ & $69.00 \pm 7.09$ \\
Education & $6.14 \pm 5.71$ & $6.43 \pm 4.54$ & $7.21 \pm 3.56$ \\
MMSE & $22.86 \pm 2.74^{\mathrm{a} * * *, \mathrm{~b} * * *}$ & $26.93 \pm 2.59^{\mathrm{b} *}$ & $29.07 \pm 0.73$ \\
Delayed recall RAVLT & $1.36 \pm 1.28^{\mathrm{a} * * *, \mathrm{~b} * * *}$ & $4.14 \pm 2.60^{\mathrm{b} * *}$ & $9.57 \pm 3.25$ \\
Recognition & & & \\
RAVLT (correct response - false positive) & $-1.07 \pm 6.33^{\mathrm{a} * * *, \mathrm{~b} * * *}$ & $4.36 \pm 4.55^{\mathrm{b} * *}$ & $11.86 \pm 1.88$ \\
Immediate memory & $5.00 \pm 1.12^{\mathrm{a} * * *, \mathrm{~b} * * *}$ & $7.01 \pm 1.41^{\mathrm{b} * *}$ & $9.86 \pm 1.33$ \\
FDS & $4.50 \pm 1.09$ & $4.50 \pm 0.76$ & $4.93 \pm 0.73$ \\
BDS & $3.21 \pm 0.80^{\mathrm{b} *}$ & $3.14 \pm 1.03^{\mathrm{b} *}$ & $4.14 \pm 1.10$ \\
\hline
\end{tabular}

aSignificantly different to aMCIs; ${ }^{b}$ Significantly different to controls; ${ }^{* * *} \mathrm{p}<0.0001 ;{ }^{* *} \mathrm{p}<0.001 ;{ }^{*} \mathrm{p}<0.05$

Table 2. Hippocampal volume $\left(\mathrm{mm}^{3}\right)$.

\begin{tabular}{lccc}
\hline & AD $($ mean \pm SD $)$ & aMCI $($ mean \pm SD $)$ & Controls $($ mean \pm SD $)$ \\
\hline Right hippocampus & $2545.18 \pm 433.49^{\text {a***}}$ & $2720.05 \pm 291.94^{\text {a***}}$ & $3245.14 \pm 266.31$ \\
Left hippocampus & $2406.07 \pm 410.89^{\text {a***}}$ & $2550.41 \pm 294.87^{\text {a***}}$ & $3058.03 \pm 217.93$ \\
\hline
\end{tabular}

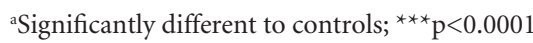

jects showing an intermediate performance in all subitems (immediate memory, delayed recall and recognition).

We found an asymmetry between HVs, with smaller mean left HV for all groups (Table 2). ANOVA and post hoc pairwise comparisons of hippocampal volumes using Tukey's test, showed a significant difference among groups, with difference between controls, AD and aMCI (ANOVA; $\mathrm{p}<0.00001$ ), although there was no difference between $\mathrm{AD}$ and aMCI groups (Table 2).

Multiple regression analysis including hippocampal volumes from all subjects (AD, aMCI and controls) as independent variables and RAVLT, FDS, BDS and MMSE as dependent variables, showed a significant relationship between volumes and scores on RAVLT subitems and MMSE $(\mathrm{p}<0.00001)$. Pearson's correlation coefficients for left and right hippocampal volumes and each test are shown in Table 3.

\section{Discussion}

Our results tended to confirm previous studies in which $\mathrm{AD}$ patients had a smaller HV compared to normal controls, while aMCI patients had intermediate atrophy (though not statistically significant in our sample). This finding is in accordance with neuropathological studies in which aMCI subjects showed an intermediate pattern of neurofibrillary changes of aging and pathologic features of very early $\mathrm{AD}$, since they showed neurofibrillary tangles in the entorhinal cortex and hippocampal formation. ${ }^{7,16}$ One possible reason for the fact that we did not find sig-
Table 3. Pearson's correlation coefficients ( $r$ ) for left and right hippocampal volumes and each test.

\begin{tabular}{lcc}
\hline Test & Right HV & Left HV \\
\hline MMSE & 0.62 & 0.62 \\
FDS & 0.22 & 0.16 \\
BDS & 0.35 & 0.27 \\
Delayed recall RAVLT & 0.66 & 0.65 \\
Recognition RAVLT & 0.51 & 0.51 \\
\hline
\end{tabular}

nificant hippocampal volume differences between mild $\mathrm{AD}$ and $\mathrm{aMCI} \mathrm{HV}$ is the clinical proximity between these two clinical entities and their close pathological relationship. Petersen et al showed that neuropathologists often characterized MCI cases as having prodromal or incipient $\mathrm{AD}$, meaning that they did not fulfill the criteria for $\mathrm{AD}$ but were suggestive of being in transition (diffuse amyloid in the neocortex and frequent neurofibrillary tangles in medial temporal lobe structures). ${ }^{7}$ In all groups, there was an asymmetry among left (more atrophic) and right hippocampus, a fact that is in disagreement with other studies, where a right-greater-than-left asymmetry is seen in normal controls, but is in accordance with other papers where MCI cases may present a reversal of this normal hippocampal asymmetry., ${ }^{4,17,18}$

We found a correlation between episodic memory and right and left HVs, confirming that quantitative assessment of medial temporal structures may serve as a surro- 
gate marker of memory performance in normal ageing as well as in $\mathrm{AD}^{6}{ }^{6,19,20}$ Measurement of other medial temporal structures such as amigdala, parahippocampal formation, entorhinal and perirhinal cortices, as well as regional hippocampal shape differences (head versus body, for example) may help further in differentiating mild cognitive impairment from initial stages of AD. ${ }^{1,18,19,21}$ Some authors have shown that hippocampal and entorhinal cortex volumes can contribute to the prediction of $\mathrm{MCI}$ conversion to $\mathrm{AD}$, although cognitive tests provide better accuracy. ${ }^{22,23}$ Attention may have influenced delayed recall performance in the $\mathrm{AD}$ group, since there was significant correlation with the BDS.

In conclusion, our preliminary findings show that there is a significant $\mathrm{HV}$ difference between $\mathrm{AD}, \mathrm{aMCI}$ and controls, but not between $\mathrm{AD}$ and $\mathrm{MCI}$; the 3 groups showed more left than right hippocampal atrophy; and episodic memory correlated with left and right HV. Our study had some limitations including the small sample size and the fact that AD patients were older than MCI patients and controls where this approached statistical significance $(\mathrm{p}=$ 0.056). Further studies employing larger sample of patients and controls as well as measures of other medial temporal structures are needed to reach definitive conclusions.

\section{Supported by grants from FAPESP.}

\section{References}

1. Markowitsch HJ. Memory and amnesia. In: Mesulam MM, editor. Principles of behavioral and cognitive neurology. New York, NY: Oxford University Press; 2000:257-293.

2. Economou A, Papageorgiou SG, Papanicolau AC. Amnesia associated with the dementias. In: Papanicolau AC, editor. The amnesias: a clinical textbook of memory disorders. New York, NY: Oxford University Press; 2006:75-110.

3. Cummings JL. Cognitive and behavioral heterogeneity in Alzheimer's disease: seeking the neurobiological basis. Neurobiol Aging 2000;21:845-861.

4. Lehéricy S, Baulac M, Chiras J, et al. Amygdalohippocampal MR volume measurement in the early stages of Alzheimer disease. AJNR Am J Neuroradiol 1994;15:927-937.

5. Visser PJ, Verhey FRJ, Hofman PAM, Scheltens P, Jolles J. Medial temporal lobe atrophy predicts Alzheimer's disease in patients with minor cognitive impairment. J Neurol Neurosurg Psychiatry 2002;72:491-497

6. Basso M, Yang J, Warren L, et al. Volumetry of amygdala and hippocampus and memory performance in Alzheimer's disease. Psychiatry Research: Neuroimaging 2006;146:251-261.

7. Petersen RC, Parisi JE, Dickson DW et al. Neuropathologic Features of Amnestic Mild Cognitive Impairment. Arch Neurol 2006;63:665-672.

8. Roth M, Huppert FA, Tym E, Mountjoy CQ. The Cambridge
Examination for Mental Disorders of the Elderly (CAMDEX). Cambridge University Press; 1988.

9. Winblad B, Palmer K, Kivipelto M, et al. Mild cognitive impairment-beyond controversies, towards a consensus: report of the International Working Group on Mild Cognitive Impairment. J Intern Med 2004;256:240-246.

10. Morris JC. The clinical dementia rating (CDR): Current version and scoring rules. Neurology 1993;43:2412-2414.

11. McKhann G, Drachman D, Folstein M, Katzman R, Price D, Stadlan EM. Clinical diagnosis of Alzheimer's disease: report of the NINCDS-ADRDA Work Group under the auspices of Department of Health and Human Services Task Force on Alzheimer's Disease. Neurology 1984;34:939-944.

12. Rey A. L'examen clinique in psychologie. Paris: Press Universitaire de France, 1964.

13. Wechsler D. Wechsler Memory Scale-Revised: Manual. USA: The Psychological Corporation, Hartcourt Brace Jovanovich Inc., 1987.

14. Brucki SMD, Nitrini R, Caramelli P, Bertolucci PHF, Okamoto IH. Sugestões para o uso do mini-exame do estado mental no Brasil. Arq Neuropsiquiatr 2003;61:777-781.

15. Watson C, Jack CR, Cendes F. Volumetric MRI: Clinical applications and contributions to the understanding of temporal lobe epilepsy. Arch Neurol 1997; 54:1521-1531.

16. Modrego PJ. Predictors of conversion to dementia of probable Alzheimer type in patients with mild cognitive impairment. Curr Alzheimer Res 2006;3:161-170.

17. Mega SM, Small GW, Xu ML, et al. Hippocampal Atrophy in Persons With Age-Associated Memory Impairment: Volumetry Within a Common Space. Psychosomatic Medicine 2002;64:487-492.

18. Killiany RJ, Moss MB, Albert MS, Sandor T, Tieman J, Jolesz F. Temporal lobe regions on magnetic resonance imaging identify patients with early Alzheimer's disease. Arch Neurol 1993;50:949-954.

19. Soininen HS, Partanen K, Pitkänen A, et al. Volumetric MRI analysis of the amygdala and hippocampus in subjects with age-associated memory impairment: Correlation to visual and verbal memory. Neurology 1994;44:1660-1668.

20. Mori E, Yoneda Y, Yamashita H, Hirono N, Ikeda M, Yamadori A. Medial temporal structures relate to memory impairment in Alzheimer's disease: an MRI volumetric study. J Neurol Neurosurg Psychiatry 1997;63:214-221.

21. Scher AI, Xu Y, Korf ES, et al. Hippocampal shape analysis in Alzheimer's disease: a population-based study. Neuroimage 2007;36:8-18.

22. Fleisher AS, Sun S, Taylor C, et al. Volumetric MRI vs clinical predictors of Alzheimer disease in mild cognitive impairment. Neurology 2008;70:191-199.

23. Devanand DP, Pradhaban G, Liu X, et al. Hippocampal and entorhinal atrophy in mild cognitive impairment: prediction of Alzheimer disease. Neurology 2007;68:828-836. 